\title{
Liberalization, Investment, and Regulation: The Key Factors for the Development of the Electronic Communications Market
}

\author{
Jonida Gjika, PhD \\ Electronic Communications and Postal Authority of Albania
}

doi: 10.19044/esj.2016.v12n1p480 URL:http://dx.doi.org/10.19044/esj.2016.v12n1p480

\begin{abstract}
The key factors for the development of the electronic communication market include partial liberalization; full, direct, or indirect investments; and competitive regulation based on transparency and non-discrimination. They are used efficiently in preventing anti-competitive practices through the use of appropriate basic instruments of transparency and non-discrimination. They are used in the proper selection of the "best practice" design and implementation of primary and secondary laws. It is an efficient regulatory framework; it creates adequate space; and they are together considered necessary in influencing the positive development of the electronic communication sector. Proper selection of the "innovative dilemma" that comes from the "technology push" in the sector and harmonization of the time required between the necessary innovation and investment, determines the quality of products/services for the sector tomorrow and its internal markets. At the same time, it determines the eligibility of the request-offer and their quality. The close connection between innovation and entrepreneurship as well as the proper implementation through investments is made tangible and measurable to the quality, price, and their persistence. When these factors are considered in harmony, it will ultimately result in effective competition in the sector. Also, their values are identified by the maximization of social welfare to increased consumer benefits.
\end{abstract}

Keywords: Liberalization, investment, regulation, competition, regulatory

\section{Introduction}

The process of liberalization of the electronic communications market is considered one of the most powerful incentives to the development of this sector. This is because it is the first major step which serves to dampen brake weight that bore alive state monopolies in this sector, in which existing products/services are offered by the operator "incumbent". The 
presence of state monopolies constitutes a significant barrier to the development of this sector. Consequently, this has become a necessity opening of this sector to other private actors who regarded the future "bone" of economic development and consumer benefits in this sector to be very important and vital.

The opening of the market through its liberalization process has made possible the increase of investment in this sector. However, the strong position of economic actors and potential who through their extension, beyond the dimensions of a market with national boundaries, serve as buffer barriers and other non-legal factors which can be properly deterred. On the other hand, it also encourages the positive development of the electronic communications sector.

National legislation was drafted by considering the principle of technological neutrality and EU regulatory framework for electronic communications. They promote the development of competition and efficient infrastructure for the provision of electronic communications services, which ultimately serve as a guarantee for maximizing the benefits to the consumer in this sector.

The art of management and effective use of limited resources basically include frequencies and numbering, the principle of technological neutrality for the construction of infrastructure services in this sector, and the basic elements of favoring sector development through transparency and legal certainty. Consequently, this has provided the necessary conditions for weakening the weight of monopolies and in stimulating the basic elements for an effective competition and protection of consumer rights.

The process of liberalization and investment to accompany its regulatory requires proper care to ensure the transition from the regime of licenses in that authorization. Therefore, this entail eliminating barriers to entry for providers of electronic communications services, which were identified by the Tariff applicable licensing (significant until the liberalization process); the need for shortening the deadlines, as well as simplification of procedures for reviewing requests for applications to escalate them only in warning notices for providing services in this sector; allowing the continuation of subsequent applications; and the fulfillment of the relevant regulatory and sectoral obligations. Distribution of authorizations to provide services in this sector in general and individual authorization, was a necessity to differentiate the right to services that require the use of limited resources such as frequencies and numbering, which are subject to individual authorization. The process of liberalization in the sector is accompanied by prudent regulatory policies to consider in both primary and secondary legislation relating to maximum protection of consumer rights. Thus, this is attained through the application of measures to 
guarantee the protection of competition, better information, access to information and to the office for consumer protection laws and regulatory acts that ensure privacy and data protection, as well as ensuring security, reliability, and the integrity of the network.

I.

\section{Liberalization}

Liberalization represents a link in a big "revolution" in the electronic communications sector. This was after breaking the barrier of strong state ownership going through the process of the privatization of large monopolies of state, from which arises the necessity for the identification of legal mechanisms and regulatory framework for economic adjustments and competitive standards in the sector. The transition from state monopoly policy in competitive politics through liberalization process constitute origins promotion of competition and thus its protection, which ultimately will become a source for the creation of new markets within the electronic communications sector. This is aimed at supporting the developmental process of their competitiveness on the basis of existential principles such as transparency and non-discrimination through the regulatory acts. Furthermore, these regulatory acts constitute a transpozion and harmonization of consumer demand and supply potential in this sector, with the final goal for a dynamic market, competitive market, growth factor development, and social welfare.

The transition from state monopoly to competitive markets and the time required for this transition is linked closely to the orientation of policies on the sector and the adoption of "best practice" in the conception of the right of the need for a regulatory framework with direct involvement in the sector. This is together with the identification of market conditions and services required, in determining the appropriate payments and state taxes.

\section{Investments}

Opening liberalization process calls to stage investors who consider market / markets demand in the sector, classify urban and rural demand and identify the quality of the application, and provides for the coverage of potential private equity or examining the possibilities of promotion for state subsidy in accordance with sectoral policies and their implementation need. Coordination investment in proper compliance with the policy of the sector and the implementation of "best practice", optimizes investment scale and eliminates unnecessary duplication of investments in increasing the efficiency of networks and infrastructure. Hence, those which are both existing and are under, at the same time, make up the consolidation and progress of interconnection services to stakeholders in the electronic 
communications sector. Thus, this ultimately results in the reduction of tariffs for consumers of products/services. The quality of the investment and approach to "best practice" in the sector, creates competition in infrastructure. However, this constitutes another step equally important that favors the liberalization process. In addition, it also reduces barriers for new entrants into the sector and enables the sharing of infrastructure and regulatory policy approach in favor of effective competition. Therefore, when considered together, these factors constitute the appropriate model for the development of competition in the sector by economize resources, infrastructure, and building the hierarchy of markets, which ultimately lead to the final product increased benefits to the consumer in an appropriate request-offer. Maximizing the benefits of the sector depends on the factor "proper investment" and the selection of "best practice" which constitutes the key to success in this regard.

Investments in the sector of electronic communications are closely associated with the level and quality of innovation. Entrepreneurship is therefore regarded as a "guide" today. The close connection between innovation and entrepreneurship and investment through proper implementation find applicability to the quality, price, and their sustainability in time. The high cost of investment in the sector, often creates innovative dilemma which naturally arises from the "technology push" in the sector. This, however, increases the complexity of choosing the right dealing with "the opportunity technology", such as innovation in relation to the request coming from the sector. Investment and its quality is among other things connected with the phase by which this investment is being carried out. Security often guarantee the right if it constitutes an "innovation" investment or creates investment dilemma.

Consequently, this makes selection difficult between the advantages and disadvantages which may have the first entrant or followers on investment.

Electronic communications sector as one of the fastest developing sectors and with a degree of innovation, significantly differentiated from many other sectors, found more in pledges of innovative dilemma and propulsion technology to make the appropriate investment or not. The level of performance required by customers with high requests, constitute the origins birth of "disruptive innovation" in the sector. Nevertheless, it is also one of the sectors with the most rapid evolution and which is in constant search of innovation technology.

\section{Regulation}

Competition is among the key factors and is influential in the development of the electronic communications sector. This is realized 
through the regulatory process and is been converted to increase the quality and the variety of products/services, as well as falling prices for their consumers. Regulation, as a process, can be considered differently as a specific form of government through a set of rules or administrative procedures in terms of monitoring and regulatory process which is ultimately made possible as the total effort of the state agencies in the direction of the economy.

Factor "adjustment" in a broader sense means a plurality of control mechanisms with the final aim of productivity growth and economic development. The process of adjustment is necessary to be in coherence with the change and development of technology, a process that will result in a direct impact on improving and increasing efficiency through reform in the domestic markets of the sector of electronic communications, as one of the right steps and fundamentals for the development of competition. An effective competition, in the right direction, ultimately maximizes social welfare by increasing benefits to customers and maximizing at the same time, the allocation of income to the sector and entrepreneurship. Furthermore, this constitutes the difference between open markets and competitive markets, and markets with a monopolistic nature. Unlike open and competitive markets, monopoly markets would otherwise produce them, which would result in the lowest completion that consumers demand both in terms of quantity, quality, and price.

Harmonization of technological progress with effective competition constitutes two separate important links for the development of the electronic communications sector. The process of adjustment is not done deliberately by the actors of the market itself. Therefore, for an effective regulation and the development of a dynamic sector, it is considered as a necessity interaction of independent authorities or otherwise known as regulatory entities.

Their independence among other things provides not only a high level of expertise, but naturally, they also affect the weakening of political influence in this sector. This in all circumstances constitutes a space influences and economic interests. The independence of regulatory authorities is associated inter alia with the decision-making independence. Operation of chain linking interacting aim is indispensable principles conservation, because a better adjustment of the internal markets of the electronic communications sector will be converted into a sector with the best and better markets with more investments. As a result, the customer will be offered products/services better in basically three of their components, namely: quality, price and variety.

Regulatory structures have been used in their daily work for the regulation and the positive development of the electronic communications 
sector of the EU directives (Regulatory framework for electronic communications in the European Union). This was drawn in different time stages, 1998 - 2003- 2007 - 2009 - 2014, but the focus on better regulation of the electronic communications sector is mainly provided in the amendment of the directives of 2003 and their replacement with the directives of 2007 and 2009. Specifically, this constitute the selection of the "best practice", and are often materialized in the directive "Better Regulation Directive 2009/140/EC" 150 which replaced three directives in 2003, respectively. These directives include Framework Directive 2002/21/EC, Access Directive 2002 / 19 / EC, and the Authorisation Directive 2002/20 / EC.

In terms of the development of the sector of electronic communications and protection of consumers rights, except the provisions of substantive law in the field for electronic communications, considerable importance have had their amendment made by DIRECTIVE 2009/136 / EC $^{151}$, which included two important directives. Specifically, this includes the Universal Service directive 2002/22 / EC and the Privacy and Electronic Communications (e-Privacy) directive 2002/58 / EC.

Electronic communications sector reflects its development through positive development of internal markets. In this regard, it should be considered as an important driver, Recommendation 2007/879 / EC (Recommendation on Relevant Markets). ${ }^{152}$ Explanatory note ${ }^{153}$ to the Recommendation on Relevant Markets and references given in

150 DIRECTIVE 2009/140/EC OF THE EUROPEAN PARLIAMENT AND OF THE COUNCIL of 25 November 2009 amending Directives 2002/21/EC on a common regulatory framework for electronic communications networks and services, 2002/19/EC on access to, and interconnection of, electronic communications networks and associated facilities, and 2002/20/EC on the authorisation of electronic communications networks and services

${ }^{151}$ DIRECTIVE 2009/136/EC OF THE EUROPEAN PARLIAMENT AND OF THE COUNCIL of 25 November 2009 amending Directive 2002/22/EC on universal service and users' rights relating to electronic communications networks and services. Directive 2002/58/EC concerning the processing of personal data and the protection of privacy in the electronic communications sector and Regulation (EC) No 2006/2004 on cooperation between national authorities responsible for the enforcement of consumer protection laws

${ }^{152}$ COMMISSION RECOMMENDATION of 17 December 2007 on relevant product and service markets within the electronic communications sector susceptible to ex ante regulation in accordance with Directive 2002/21/EC of the European Parliament and of the Council on a common regulatory framework for electronic communications networks and services

${ }^{153}$ EXPLANATORY NOTE Accompanying document to the Commission Recommendation on Relevant Product and Service Markets within the

electronic communications sector susceptible to ex ante regulation in accordance with Directive 2002/21/EC of the European Parliament and of the Council on a common regulatory framework for electronic communications networks and services 
Recommendation 2009/396/EC (Recommendation on Termination Rates) ${ }^{154}$ associated with the "explanatory note to the Recommendation on Termination Rates" ${ }^{155}$ which are taken together and used by the regulatory structures for the regulation of internal markets in the electronic communications sector. Therefore, it has served as a compass for orienting factor "adjustment market". This is achieved by giving the development of effective competition in these markets a strong hand and consequently increasing the opportunities and benefits for consumers.

Consequently, the following should be considered as a good will of the regulatory structures to implement in their own countries: directives of the EU and the need for harmonization of the regulatory framework of the $\mathrm{EU}$, the obligation for application in all member states of the EU, as well as the definition of this regulatory framework as essential to success in the development of the sector of electronic communications. Thus, this is regardless of the inclusion, or not, in the national legislation in other countries, adapted by the moment generated by the EU limit for implementation. This is because the EU directives are mandatory for the implementation only to the member countries of the EU. Also, other countries (not members of the EU) were given the opportunities in certain areas, to adopt and implement other rules which are under development and national conditions.

The trend for a better adjustment and harmonization with the other two factors, investment and liberalization, constitute major interacting steps for the development of the electronic communications sector.

\section{Conclusion}

Fundamental factors with a direct impact on the development of the electronic communications sector with priority development of effective competition detailed above can be summarized as:

- Liberalization, investment, and regulation are identified as the most important factor that generates positive effects on the development of competition, having transformed the nature of markets from monopoly to competitive markets;

- Enable the creation of better conditions for investors and service providers;

- Allow increase in the number of entrepreneurs in the sector of electronic communications, and therefore increase the variety of

${ }^{154}$ COMMISSION RECOMMENDATION of 7 May 2009 on the Regulatory Treatment of Fixed and Mobile Termination Rates in the EU (2009/396/EC)

155 COMMISSION RECOMMENDATION on the Regulatory Treatment of Fixed and Mobile Termination Rates in the EU EXPLANATORY NOTE $\{\mathrm{C}(2009) 3359$ final $\}$ \{SEC(2009) 599\} 
products/services and continual improvement of their quality and alignment of demand and in satisfying its consumer in terms of quality and price;

- Creating more consumer choices and this is a result of better regulation, better markets, more investment, from products/services better; - Available to effectively prevent anti-competitive practices, using appropriately efficient instruments of transparency and non-discrimination, as well as the selection of appropriate "best practice" and which are under the efficient regulator, which when they are together, affects the positive development of the sector.

\section{References:}

Directive 2009/140/EC of the European Parliament and of the Council of 25 November 2009 amending Directives 2002/21/EC on a common regulatory framework for electronic communications networks and services, 2002/19/EC on access to, and interconnection of, electronic communications networks and associated facilities, and 2002/20/EC on the authorisation of electronic communications networks and services

Directive 2009/136/EC of the European Parliament and of the Council of 25 November 2009 amending Directive 2002/22/EC on universal service and users' rights relating to electronic communications networks and services. Directive 2002/58/EC concerning the processing of personal data and the protection of privacy in the electronic communications sector and Regulation (EC) No 2006/2004 on cooperation between national authorities responsible for the enforcement of consumer protection laws

Commission Recommendation of 17 December 2007 on relevant product and service markets within the electronic communications sector susceptible to ex ante regulation in accordance with Directive 2002/21/EC of the European Parliament and of the Council on a common regulatory framework for electronic communications networks and services

Explanatory note Accompanying document to the Commission Recommendation on Relevant Product and Service Markets within the electronic communications sector susceptible to ex ante regulation in accordance with Directive 2002/21/EC of the European Parliament and of the Council on a common regulatory framework for electronic communications networks and services

Commission Recommendation of 7 May 2009 on the Regulatory Treatment of Fixed and Mobile Termination Rates in the EU (2009/396/EC)

Commission Recommendation on the Regulatory Treatment of Fixed and Mobile Termination Rates in the eu explanatory note $\{\mathrm{C}(2009) 3359$ final $\}$ \{SEC(2009) 599\} 